\title{
METHOD DEVELOPMENT AND VALIDATION STUDY FOR QUANTITATIVE DETERMINATION OF GENOTOXIC IMPURITY AND ITS PRECURSOR IN FLUCONAZOLE SAMPLE BY LIQUID CHROMATOGRAPHY-TANDEM MASS SPECTROMETRY
}

\author{
L. NARASIMHA RAO K. ${ }^{1}$, N. DEVANNA1, K. V. N. SURESH REDDY2,* \\ 1Department of Chemistry, Jawaharlal Nehru Technological University Anantapur, Anantapur 515002, Andhra Pradesh, India, \\ 2Department of Chemistry, GITAM Institute of Technology, GITAM University, Visakhapatnam 530045, Andhra Pradesh, India \\ Email: soorikachi@gmail.com
}

Received: 16 Aug 2016 Revised and Accepted: 05 Oct 2016

\section{ABSTRACT}

Objective: The objective of this work is method development and validation study for quantitative determination of 1-[2-(2,4-difluorophenyl)-2,3epoxypropyl]-1H-1,2,4-triazole, a genotoxic impurity and its precursor in a fluconazole drug sample by liquid chromatography-tandem mass spectrometry.

Methods: LC-MS/MS analysis of these impurities was performed on Hypersil BDS C18 (100 mm x $4.0 \mathrm{~mm}, 3 \mu \mathrm{m})$ column. $5 \mathrm{mmol}$ ammonium acetate and acetonitrile in the ratio of $65: 35(\mathrm{v} / \mathrm{v})$ was used as the mobile phase with a flow rate of $0.4 \mathrm{ml} / \mathrm{min}$. The developed method was accomplished with a short run time of $10 \mathrm{~min}$. Triple quadrupole mass detector coupled with positive electrospray ionization was used for the quantification of genotoxic impurities in multiple reaction monitoring (MRM).

Results: The method was validated as per International Conference on Harmonization (ICH) guidelines. The method was linear in the range of 0.30 $\mu \mathrm{g} / \mathrm{g}$ to $11.37 \mu \mathrm{g} / \mathrm{g}$ for impurity A and $0.30 \mu \mathrm{g} / \mathrm{g}$ to $11.34 \mu \mathrm{g} / \mathrm{g}$ for impurity B with a correlation coefficient of 0.999 . The accuracy of the method was in the range of $98.25 \%$ to $100.53 \%$ for both impurities.

Conclusion: A specific, selective, highly sensitive and more accurate analytical method using LC-MS/MS coupled with positive electrospray ionization has been developed for the quantification of genotoxic impurity (1-[2-(2,4-difluorophenyl)-2,3-epoxypropyl]-1H-1,2,4-triazole) and its precursor (1-(2,4-difluorophenyl)-2-[1,2,4]triazol-1-yl-ethanone) at $0.3 \mu \mathrm{g} / \mathrm{g}$ with respect to the $5.0 \mathrm{mg} / \mathrm{ml}$ of fluconazole.

Keywords: Fluconazole, Genotoxic Impurity, LC/MS/MS, Method Development, Validation

(C) 2016 The Authors. Published by Innovare Academic Sciences Pvt Ltd. This is an open access article under the CC BY license (http://creativecommons.org/licenses/by/4. 0/] DOI: http://dx.doi.org/10.22159/ijpps.2016v8i12.14727.

\section{INTRODUCTION}

Recently, genotoxic impurities manifestation in active pharmaceutical ingredient (API), as well as products of drugs, received more attention by industries and various governing agencies because of their toxic effect on human health [1]. Even lower concentration $(<1 \mathrm{ppm})$ of genotoxic impurities causes hereditary transformations, chromosome disruptions and leads to oncological diseases. In general, the sources of organic genotoxic impurities in drugs are starting materials, reagents, intermediates, degradation products and by-products of the production of the drug. As per the recommendations of ICH, there is a need to remove the impurities or to reduce their content to a safe level. As per the guidelines of ICH M7, FDA and EMA, the acceptable level of genotoxic impurities is calculated based on the toxicological concern and is considered safe for lifetime use is $1.5 \mu \mathrm{g}$ day $-1 \mathrm{R}-4]$. Hence there is a need for chemists to focus development of the manufacturing process of these drugs on minimizing such genotoxic impurities, as it is not possible to eliminate genotoxic impurities completely from the synthetic scheme.

Fluconazole is used for the treatment of systemic and superficial fungal infections, by inhibiting the action of fungal cytochrome enzyme [5-7]. Fluconazole active pharmaceutical ingredient was commercially prepared by reacting its intermediate $1-[2-(2,4-$ difluor-ophenyl)-2,3-epoxypropyl]-1H-1,2,4-triazole, genotoxic impurity] with triazole in the presence of a base [8]. The scheme of the synthesis of fluconazole is presented in fig. 1. From the scheme given in fig. 1, an intermediate of the fluconazole was prepared from 1-(2,4-difluorophenyl)-2-[1,2,4]triazol-1-yl-ethanone (precursor of intermediate, in the scheme it is represented as compound 3 ). As per the study of Muller et al. [9], this intermediate belongs to group 2 of genotoxic impurities and may cause the unwanted genotoxicity and carcinogenicity. According to the study of micronucleus assay by Fucic et al. [10], fluconazole was caused genome damage in young animals and in new-born pups. So, quantitative determination of this genotoxic impurity and its precursor in fluconazole at lower levels is important for organic chemists to control them during the synthesis of fluconazole. Here onwards the impurities, 1-(2,4-difluorophenyl)$2-[1,2,4]$ triazol-1-yl-ethanone (precursor of genotoxic impurity) and 1-[2-(2,4-difluorophenyl)-2,3-epoxypropyl]-1H-1,2,4-triazole (genotoxic impurity) are abbreviated as impurity A and impurity B in the manuscript.

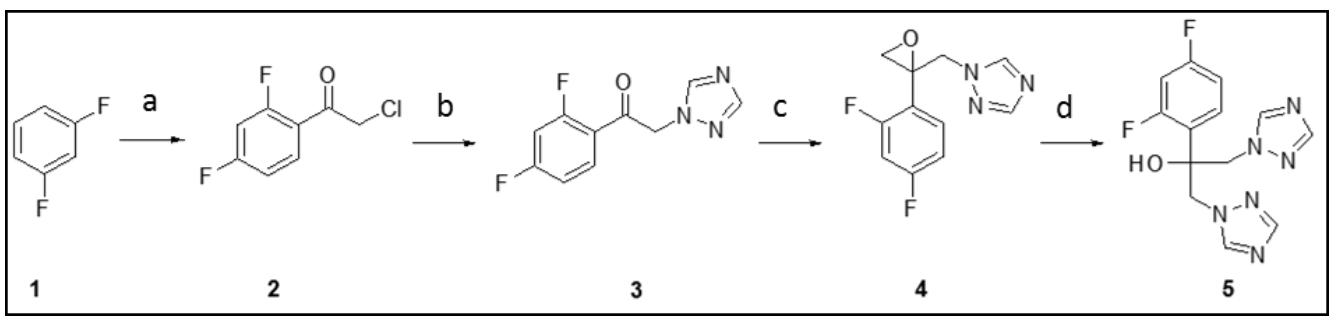

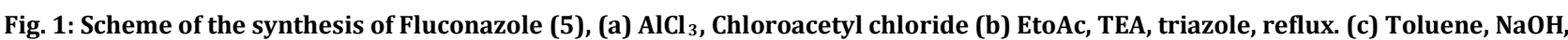
TMSOI, triazole, reflux (d) DMF, triazole, anhy. $\mathrm{K}_{2} \mathrm{CO}_{3}, 90^{\circ} \mathrm{C}, 2.5 \mathrm{~h}$. genotoxic impurity (4) and precursor of genotoxic impurity (3) 
As per the concern of regulatory agencies, the amount of genotoxic impurities in the drug substance should be limited to $7.5 \mu \mathrm{g} / \mathrm{g}$ by assuming of daily dosage as $200 \mathrm{mg} /$ day dose. A method capable of detecting such a lower level is a great challenge for the analyst. Development of a method for the determination of genotoxic impurities at a lower level using conventional analytical instruments (ultraviolet-visible spectrophotometry, gas chromatography and high-performance liquid chromatography) is a difficult task in the pharmaceutical industry as the sensitivity of these instruments is low. Hence, the sensitivity of analytical equipment must be increased in order to determine impurities at lower levels ( $\leq 1 \mathrm{ppm})$. This can be achieved by combining chromatography with mass spectrometry (MS). Because of reliability and high sensitivity of chromatography methods coupled with mass spectrometry (LC/MS/MS or GC/MS), recently many authors used these methods for the determination of organic genotoxic impurities [11-20]. The present study is an attempt to develop LC/MS/MS method for the determination of both the genotoxic impurity and its precursor. The literature survey revealed that some spectrophotometric and HPLC methods were developed for the determination of fluconazole in formulations as well as bio samples [21-28], but no method has been found for the determination of genotoxic impurities at low levels $(\mu \mathrm{g} / \mathrm{g})$.

\section{MATERIALS AND METHODS}

\section{Chemicals and reagents}

Acetonitrile and ammonium acetate of HPLC grade were purchased from Merck (Mumbai, India). Analytical grade formic acid, trifluoroacetic acid and methanol were supplied by SD Fine Chemicals Limited (Mumbai, India). Purified water was collected through Milli-Q Plus water purification system (Millipore, Milford ford, MA, USA). Fluconazole API and reference substances of genotoxic impurities were obtained from A. R. Life Sciences Pvt. Ltd., (Hyderabad, India).

\section{LC-MS/MS system conditions}

The MS of LC-MS/MS system was an Applied Biosystems AB Sciex API 4000 model (Switzerland). The HPLC consisting an LC-20AD binary gradient pump, an SPD-10AVP UV detector, SIL-10HTC autosampler and a column oven CTO-10ASVP (Shimadzu Corporation, Kyoto, Japan) was used for method development and validation. Data acquisition and processing were conducted using the Analyst 1.5.1 software on a Dell computer (Digital equipment Co). Hypersil BDS C18 $(100 \mathrm{~mm} \times 4.0 \mathrm{~mm}, 3 \mu \mathrm{m})$ column was used for the analysis.

\section{Operating conditions of LC/MS/MS}

The analytical column used in LC/MS/MS was Hypersil BDS C18 (100 $\mathrm{mm} \times 4.0 \mathrm{~mm}$ ) $3 \mu \mathrm{m}$ column (Thermo Co, USA) in isocratic mode. 5 mmol ammonium acetate and acetonitrile in the ratio of $65: 35(\mathrm{v} / \mathrm{v})$ was used as a mobile phase. The flow rate was $0.4 \mathrm{ml} / \mathrm{min}$, with the flow rate split down to $0.1 \mathrm{ml} / \mathrm{min}$ into the MS source. The column oven temperature was maintained at $40{ }^{\circ} \mathrm{C}$; the sample cooler temperature was $5{ }^{\circ} \mathrm{C}$ and the wavelength were set at $260 \mathrm{~nm}$. The injection volume was $10 \mu \mathrm{l}$. Positive ion electrospray ionization probe in multiple reaction monitoring (MRM) modes was used in MS method for quantification of impurities in fluconazole drug substance. In this method impurity-A was monitored with its molecular ion $[\mathrm{M}+\mathrm{H}]^{+} \mathrm{m} / \mathrm{z}$ 224.2 and daughter ion $\mathrm{m} / \mathrm{z} 127.2$ (224.2-127.2); impurity-B was monitored with its molecular ion $[\mathrm{M}+\mathrm{H}]+\mathrm{m} / \mathrm{z} 238.2$ (protonated) and daughter ion $\mathrm{m} / \mathrm{z} 141.2$ (238.2-141.2) and fluconazole was monitored with its molecular ion $[\mathrm{M}+\mathrm{H}]+\mathrm{m} / \mathrm{z}$ 307. The ion spray voltage (V), declustering potential and entrance potential was kept as $4500 \mathrm{~V}, 50 \mathrm{~V}$ and $10 \mathrm{~V}$ respectively. The ion source gas 1 and ion source gas 2 nebulization pressures (psi) were maintained at 35,30 and 14 respectively. This method is suitable for the quantification of impurity $\mathrm{A}$ and impurity B both in reaction monitoring samples as well as fluconazole active pharmaceutical ingredient.

\section{Preparation of standard and sample solutions}

A stock solution of $0.1 \mathrm{mg} / \mathrm{ml}$ was prepared by dissolving appropriate amount of impurity-A and impurity-B in methanol. Preparation of stock standard solution of $0.001 \mathrm{mg} / \mathrm{ml}$ was attained by dilution with methanol. Finally, desired concentration $(7.5 \mu \mathrm{g} / \mathrm{g})$ of standard solution with respect to the sample concentration of 5 $\mathrm{mg} / \mathrm{ml}$ was prepared by the diluting standard stock solution to 10 $\mathrm{ml}$ with methanol. Fluconazole sample was prepared with the concentration of $5 \mathrm{mg} / \mathrm{ml}$. The LOQ spiked sample was prepared by adding the impurities at LOQ level.

\section{RESULTS AND DISCUSSION}

\section{Analytical method development}

The main aim of the LC-MS/MS method in this study was to separate and quantify impurity-A and impurity-B in the fluconazole active pharmaceutical ingredient. The present method was developed by testing different stationary phases to achieve proper separation of analytes and drug substance. Various columns like Kromasil C-8, Hypersil BDS C8, Zorbax Rx C8 and Hypersil BDS C18 of different dimensions were evaluated. Hypersil BDS C8 and Zorbax Rx C8 were not found suitable as the response of analytes was less and the impurity peaks were not well resolved among them as well as from the drug substance peak. The resolution between fluconazole and impurities were poor with Kromasil C8 and Zorbax Rx C8 columns. On Hypersil BDS C18 column of dimension $100 \mathrm{~mm} \times 4.0 \mathrm{~mm}, 3.0$ $\mu \mathrm{m}$, the separation and response for two impurities were found to be good. On this column, fluconazole, impurity A and impurity B were eluted at $2.31 \mathrm{~min}, 3.84 \mathrm{~min}$ and $4.75 \mathrm{~min}$, respectively and separated from each other and from the active pharmaceutical ingredient. In addition, different mobile phases containing buffers such as formic acid, trifluoroacetic acid and ammonium acetate with different organic modifiers like acetonitrile and methanol have been tested. Trifluoroacetic acid in buffer was suppressed the ionization. Finally, good separation was achieved on a Hypersil BDS C18 (100 $\mathrm{mm} \times 4.0 \mathrm{~mm}$ ) $3 \mu \mathrm{m}$ column (Thermo Co, USA) in an isocratic mode using $5 \mathrm{mmol}$ ammonium acetate and acetonitrile in the ratio of $65: 35(\mathrm{v} / \mathrm{v})$. The presence of ammonium acetate in mobile phase enhances ionization and detection. The flow rate was $0.4 \mathrm{ml} / \mathrm{min}$, with the flow rate split down to $0.1 \mathrm{ml} / \mathrm{min}$ into the MS source. Here in this work methanol is used as diluent.

\section{Method validation}

\section{Specificity}

Solutions of fluconazole, impurity-A and impurity-B were prepared separately at a concentration of about $0.01 \mathrm{mg} / \mathrm{ml}$ in the diluent and injected. The corresponding chromatograms of fluconazole and its impurities are presented in fig. 2. The chromatograms in fig. 2 showed that fluconazole, impurity A and impurity B peaks were eluted at 2.31, 3.84 and $4.75 \mathrm{~min}$, respectively. The peaks of impurities with fluconazole were well separated, and no interference was observed.

\section{Determination of LOD and LOQ}

The limit of detection (LOD) and limit of quantification (LOQ) were calculated from $\mathrm{S} / \mathrm{N}$ (signal to noise) ratios. In this process the concentrations were reduced sequentially, such that they yield S/N ratio as 9.7 and 10.1, respectively, for impurity-A and impurity-B. The LOQ of $0.3 \mu \mathrm{g} / \mathrm{g}$ is typical for the impurity-A and impurity-B, with a LOD of $0.1 \mu \mathrm{g} / \mathrm{g}$ approximately three times less than LOQ. The precision of six injections of a sample containing $0.3 \mu \mathrm{g} / \mathrm{g}$ of impurity A and impurity B (with respect to the API concentration 5 $\mathrm{mg} / \mathrm{ml}$ ) at LOQ level was below $1.5 \%$ RSD. The determined LOD, LOQ chromatograms and LOQ spiked chromatograms are shown in fig. 3-5. The found LOQ values are sufficient to quantify these impurities at ultra-level in the fluconazole API as per the limits defined by pharma regulating agencies. As per the literature survey, no high-performance liquid chromatography method has been found for the determination of these potential impurities in fluconazole active pharmaceutical ingredient. Al-Rimawi [23] described a highperformance liquid chromatography-ultraviolet (HPLC-UV) method for the detection of other related compounds at $260 \mathrm{~nm}$ which, unfortunately, is not sensitive enough to quantify the impurities in the $\mu \mathrm{g} / \mathrm{g}$ range. But the present LC/MS/MS method offers great sensitive detection of impurities at $0.1 \mu \mathrm{g} / \mathrm{g}(0.5 \mathrm{ng} / \mathrm{ml})$, when compared to a high performance chromatography technique of the detection limit of $100 \mu \mathrm{g} / \mathrm{g}(1 \mu \mathrm{g} / \mathrm{ml})$. Existing methods such as HPLC with UV detection and GC with FID detection have some drawbacks as retention times can vary, uncertainty can arise as to whether a peak at a new retention time is a new impurity and these 
methods certainly needed some other method to characterize the impurities online. But the current developed LC/MS/MS method can directly use to quantify impurities at lower levels without above mentioned difficulties.

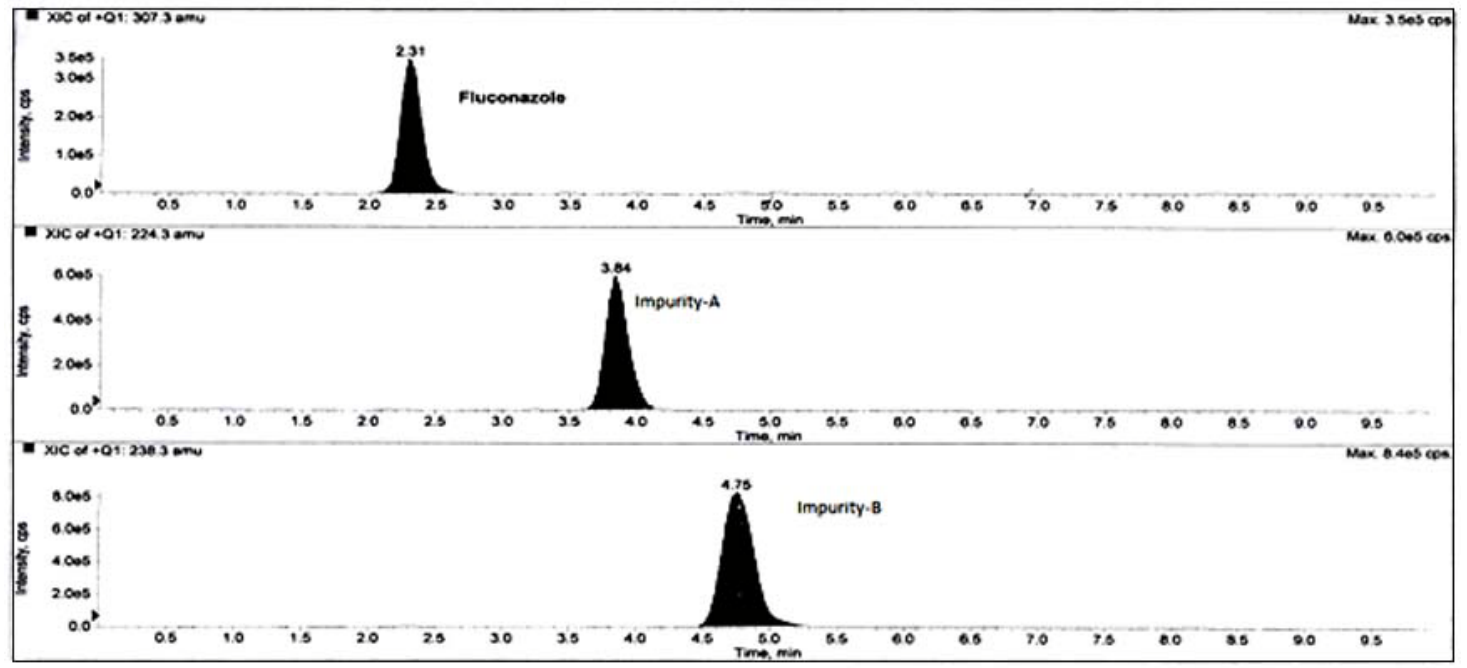

Fig. 2: Chromatograms of simultaneous determination of fluconazole and its impurities

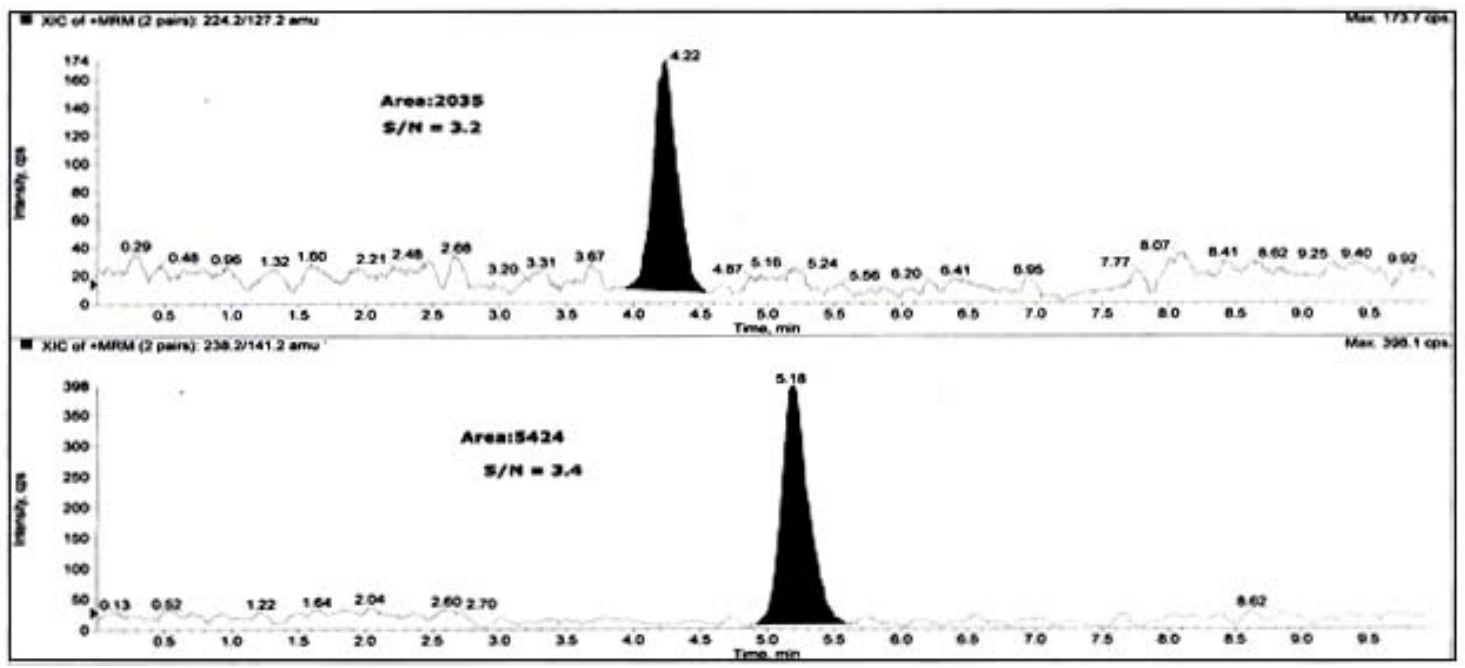

Fig. 3: LOD chromatograms of impurity-A (above) and impurity-B (below)

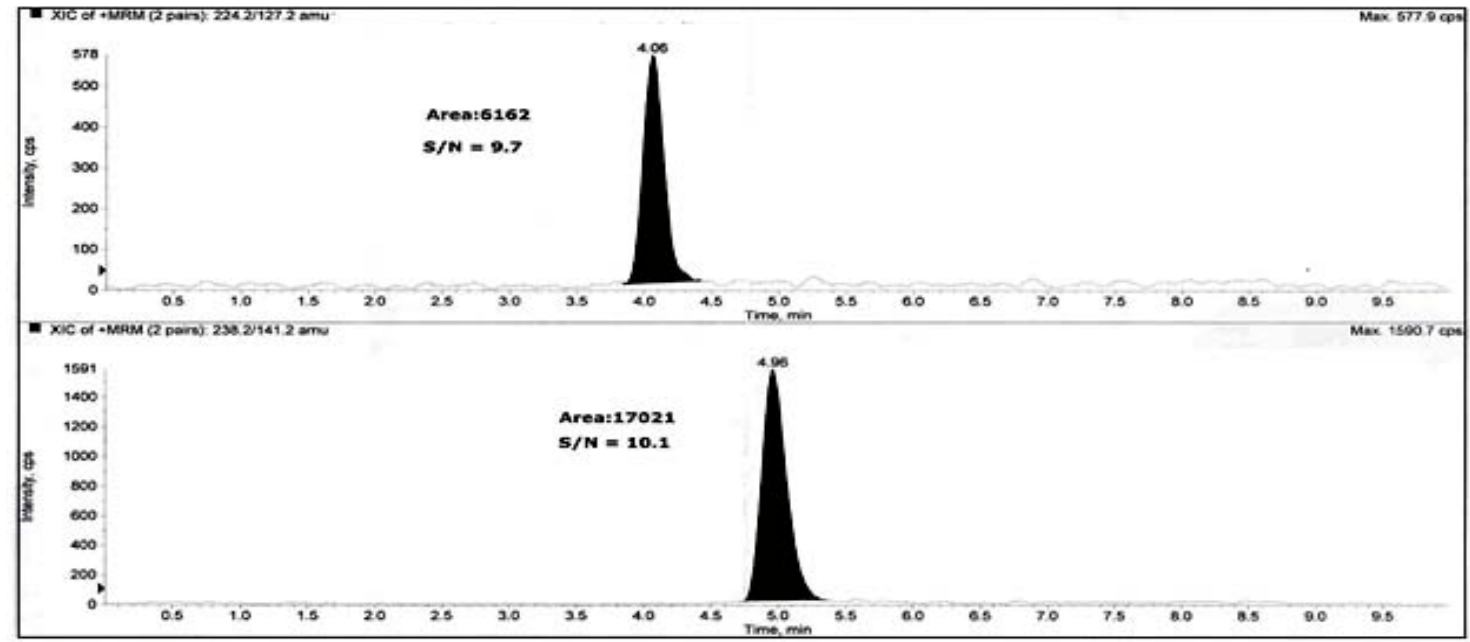

Fig. 4: LOQ chromatograms of impurity-A (above) and impurity-B (below) 


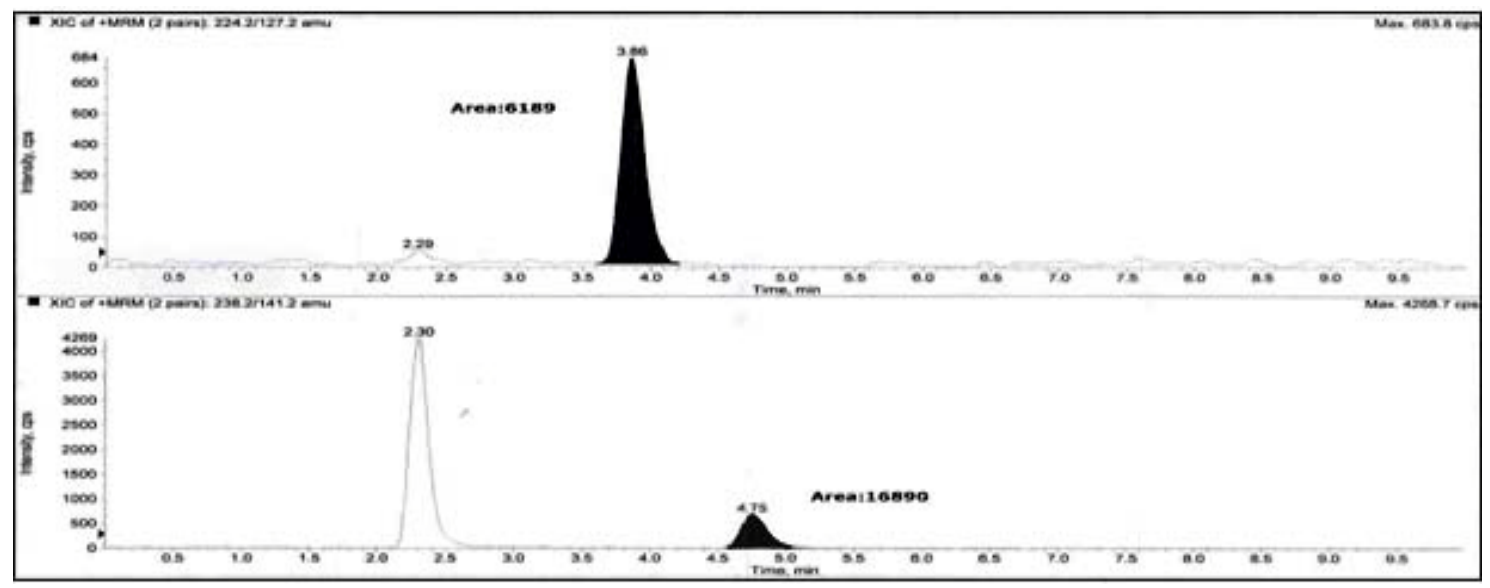

Fig. 5: LOQ spiked chromatogram of impurity A (above) impurity B (below)

\section{Linearity}

The linearity of genotoxic impurity and its precursor satisfactorily demonstrated with a six-point calibration graph between LOQ to $150 \%$ of analyte concentrations $(60,80,100,120$ and $150 \%)$. The relation between impurity concentration $(\mathrm{x})$ and its corresponding peak area (y) was expressed by the equation $y=m x+b$. The slope, intercept, and correlation coefficient values are derived from linear least-square regression analysis, and the data are presented in table 1. The linearity results tabulated in table 1 indicate that an excellent correlation exists between the peak areas and the concentration of impurity-A and impurity-B.

\section{Recovery studies}

The accuracy of the method was obtained by recovery studies. In this process, recovery studies were performed in triplicate at LOQ level, $50 \%, 100 \%$ and $150 \%$. Then the percentage recoveries were calculated to evaluate the accuracy of the method and values are shown in table 2. Excellent recovery values were obtained for impurity-A (98.55-100.20\%) and impurity-B (98.25-100.53\%). Results of accuracy studies in table 2 confirmed that excellent recoveries were obtained with \% RSD which is less than 1.2 .

\section{Precision and ruggedness}

Method precision was determined from the results of six determinations by injecting six freshly prepared solutions containing $7.5 \mu \mathrm{g} / \mathrm{g}$ of each, impurity-A and impurity-B on the same day. The results of method precision are shown in table 3 . Ruggedness was carried out such as method precision with different days, different columns and different lots of mobile phase and the results are shown in table 3 . Results showed in table 3 confirm that both the precision and ruggedness of the developed method are good. Lower \% RSD values of ruggedness indicate that the method was well suited for different laboratory conditions.

Table 1: Linearity of two impurities from LOQ level to $150 \%$

\begin{tabular}{lllll}
\hline \% Level & Impurity-A concentration $(\boldsymbol{\mu g} / \mathbf{g})$ & Peak area & Impurity-B concentration $(\boldsymbol{\mu g} / \mathbf{g})$ & Peak area \\
\hline LOQ & 0.30 & 6215 & 0.30 & 17150 \\
$60 \%$ & 4.51 & 93005 & 4.54 & 255125 \\
$80 \%$ & 6.07 & 123445 & 6.05 & 342500 \\
$100 \%$ & 7.58 & 152330 & 7.56 & 418125 \\
$120 \%$ & 9.10 & 186554 & 9.07 & 516512 \\
$150 \%$ & 11.37 & 231445 & 11.34 & 642125 \\
& Slope & 20332.1935 & Slope & 56620.8882 \\
& Intercept & 234.8026 & Intercept & -1440.0798 \\
& Correlation & 0.9999 & Correlation & 0.9998 \\
\hline
\end{tabular}

Table 2: Accuracy of the method for two impurities (n=3)

\begin{tabular}{|c|c|c|c|c|c|c|c|c|}
\hline \multirow[t]{3}{*}{ \% Level } & \multicolumn{4}{|l|}{ Impurity-A } & \multicolumn{4}{|l|}{ Impurity-B } \\
\hline & \multirow[t]{2}{*}{ Added amount } & \multirow{2}{*}{$\begin{array}{l}\text { Found amount } \\
\text { mean }(\mu \mathrm{g} / \mathrm{g}) \pm S D\end{array}$} & \multicolumn{2}{|c|}{ Recovery (\%) } & \multirow[t]{2}{*}{ Added amount } & \multirow{2}{*}{$\begin{array}{l}\text { Found amount } \\
\text { mean }(\mu \mathrm{g} / g) \pm S D\end{array}$} & \multicolumn{2}{|l|}{ Recovery (\%) } \\
\hline & & & mean \pm SD & RSD (\%) & & & mean \pm SD & RSD (\%) \\
\hline LOQ & 0.30 & $0.30 \pm 0.002$ & $99.27 \pm 0.648$ & 0.6 & 0.30 & $0.30 \pm 0.0036$ & $99.20 \pm 1.180$ & 1.2 \\
\hline 50 & 3.78 & $3.76 \pm 0.026$ & $99.38 \pm 0.682$ & 0.7 & 3.78 & $3.74 \pm 0.0137$ & $99.13 \pm 0.362$ & 0.4 \\
\hline 100 & 7.56 & $7.55 \pm 0.041$ & $99.70 \pm 0.540$ & 0.5 & 7.56 & $7.52 \pm 0.0409$ & $99.53 \pm 0.541$ & 0.5 \\
\hline 150 & 11.34 & $11.29 \pm 0.078$ & $99.28 \pm 0.692$ & 0.7 & 11.34 & $11.33 \pm 0.028$ & $99.95 \pm 0.246$ & 0.2 \\
\hline
\end{tabular}

\section{Robustness}

The robustness of the method was studied by intentional changes in flow rate of the mobile phase and column temperature. The flow rate of the mobile phase was altered by 0.04 units, i.e. 0.36 to 0.44 $\mathrm{ml} / \mathrm{min}$. The effect of column temperature on the analysis was studied at $38{ }^{\circ} \mathrm{C}$ and $42{ }^{\circ} \mathrm{C}$ (temperature altered by 2 units). The robustness of the proposed method was evaluated by the changing composition of buffer solution with $\pm 5 \%$. All the above intentional changes did not show any significant differences between the columns and the separation of the two impurities with fluconazole. The results revealed that these changes do not impact on chromatographic performance.

\section{Solution stability}

The solution stability of fluconazole and two impurities was tested by monitoring the peak areas and retention times over a period of 2 $\mathrm{d}$. The results showed that the retention times and peak areas of fluconazole and two impurities were with relative standard 
deviation of lower than two and that no significant degradation is observed within the given period, indicating that the solutions are stable. The solution stability study revealed that the stability of impurity-A and impurity-B was satisfactory up to $48 \mathrm{~h}$.

\section{Method application}

This method is applied to the real fluconazole sample and chromatograms are shown in fig. 6 which indicate that no impurities are found in fluconazole sample.

Table 3: Method precision and intermediate precision for two impurities

\begin{tabular}{|c|c|c|c|c|c|c|c|c|}
\hline \multirow[t]{3}{*}{ S. No. } & \multicolumn{4}{|c|}{ Method precision } & \multicolumn{4}{|c|}{ Ruggedness } \\
\hline & \multicolumn{2}{|c|}{ Impurity A } & \multicolumn{2}{|c|}{ Impurity B } & \multicolumn{2}{|c|}{ Impurity A } & \multicolumn{2}{|c|}{ Impurity B } \\
\hline & $\mu \mathrm{g} / \mathrm{g}$ & $\%$ & $\mu \mathrm{g} / \mathrm{g}$ & $\%$ & $\mu \mathrm{g} / \mathrm{g}$ & $\%$ & $\mu \mathrm{g} / \mathrm{g}$ & $\%$ \\
\hline 1 & 7.52 & 99.13 & 7.52 & 99.42 & 7.53 & 99.93 & 7.45 & 99.30 \\
\hline 2 & 7.57 & 99.78 & 7.57 & 100.12 & 7.52 & 99.76 & 7.55 & 100.65 \\
\hline 3 & 7.6 & 100.20 & 7.49 & 99.06 & 7.53 & 99.95 & 7.68 & 102.34 \\
\hline 4 & 7.59 & 100.12 & 7.46 & 98.71 & 7.56 & 100.32 & 7.66 & 102.18 \\
\hline 5 & 7.53 & 99.29 & 7.49 & 99.04 & 7.6 & 100.79 & 7.63 & 101.72 \\
\hline 6 & 7.57 & 99.78 & 7.63 & 100.87 & 7.62 & 101.08 & 7.66 & 102.09 \\
\hline Mean & 7.56 & 99.72 & 7.53 & 99.54 & 7.56 & 100.31 & 7.61 & 101.38 \\
\hline SD & 0.032 & 0.432 & 0.063 & 0.810 & 0.041 & 0.530 & 0.089 & 1.187 \\
\hline \%RSD & 0.42 & 0.4 & 0.83 & 0.8 & 0.55 & 0.5 & 1.17 & 1.2 \\
\hline
\end{tabular}

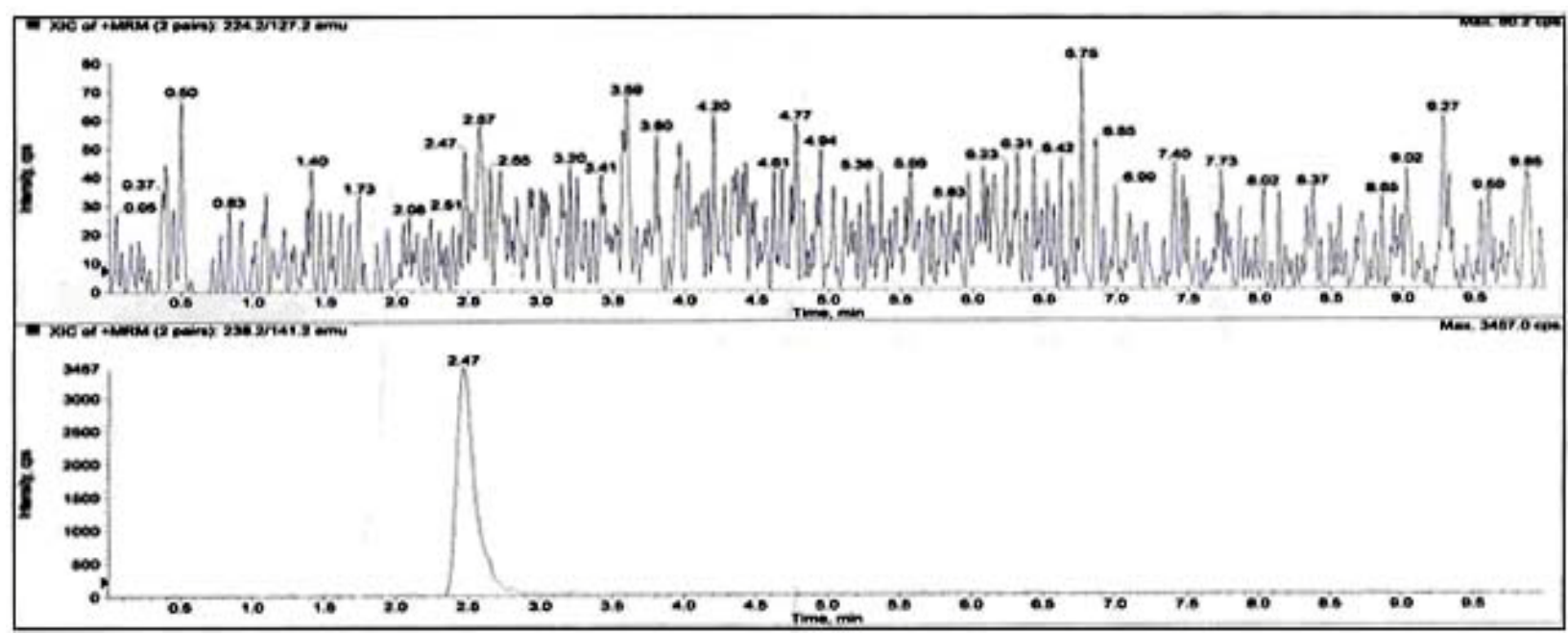

Fig. 6: Sample chromatogram

\section{CONCLUSION}

A specific, selective, highly sensitive and more accurate analytical method using LC-MS/MS coupled with positive electrospray ionization has been developed for the quantification of genotoxic impurity, 1-[2-(2,4-difluorophenyl)-2,3-epoxypropyl]-1H-1,2,4triazole and its precursor, 1-(2,4-difluorophenyl)-2-[1,2,4]triazol-1yl-ethanone at $0.3 \mu \mathrm{g} / \mathrm{g}$ in fluconazole API. The method has been validated for specificity, linearity, accuracy, precision, robustness and stability. This method is able to detect the impurities in presence of other impurities and main drug. The method is more linear in the range of $0.30 \mu \mathrm{g} / \mathrm{g}$ to $11.37 \mu \mathrm{g} / \mathrm{g}$ for impurity $\mathrm{A}$ and $0.30 \mu \mathrm{g} / \mathrm{g}$ to $11.34 \mu \mathrm{g} / \mathrm{g}$ for impurity B with a correlation coefficient not less than 0.999 . The accuracy of the method is in the range of $98.25 \%$ to $100.53 \%$ for both impurities. It has been demonstrated that this method is sensitive with a limit of detection (LOD) of 0.1 $\mu \mathrm{g} / \mathrm{g}$ of genotoxic impurity. The information presented here could be useful for monitoring of impurity-A and impurity-B in fluconazole sample. This method is useful for the genotoxic determination impurities during manufacture of fluconazole API.

\section{ACKNOWLEDGEMENT}

The authors wish to thank A. R. Life Sciences Pvt. Ltd., Hyderabad for providing the standards of fluconazole and impurities for this work.

\section{CONFLICTS OF INTERESTS}

Declared none

\section{REFERENCES}

1. Gyorgy Szekely, Miriam C, Amores de Sousa, Marco Gil, Frederico Castelo Ferreira, William Heggie, et al. Genotoxic impurities in pharmaceutical manufacturing: sources, regulations, and mitigation. Chem Rev 2015,115:8182-229.

2. European Medicines Agency, Evaluation of medicines for human use, the committee for medicinal products for human use (CHMP), Guideline on the limits of genotoxic impurities; 2006. Available from:http://www.ema.europa.eu/docs/en_GB/document_library /Scientific_guideline/2009/09/WC500002903.pdf. [Last accessed on 10 Jul 2016]

3. U S Food and Drug Administration, Guidance for industry genotoxic and carcinogenic impurities in drug substances and products: recommended approaches, 2008. US Department of Health and Human Services, Food and Drug Administration, Center for Drug Evaluation and Research (CDER); 2008.

4. Assessment and control of DNA reactive (mutagenic) impurities in pharmaceuticals to limit potential carcinogenic risk, M7 ICH Harmonized Tripartite Guideline. Available from: http://www.ich.org/fileadmin/Public_Web_Site/ICHProducts/Gui delines/Multidisciplinary/M7/M7_Step 4.pdf. [Last accessed on 25 Aug 2014]

5. Rogers TE, Galgiani JN. Activity of fluconazole (UK 49,858) and ketoconazole against Candida albicans in vitro and in vivo. Antimicrob Agents Chemother 1986;30:418-22. 
6. Humphrey MJ, Jevons S, Tarbit MH. Pharmacokinetic evaluation of UK-49,858, a metabolically stable triazole antifungal drug, in animals and humans. Antimicrob Agents Chemother 1985; 28:648-53.

7. Pfizer Australia Pty Ltd. Diflucan (Australian Approved Product Information). West Ryde (NSW): Pfizer Australia; 2004.

8. Vasantha M, Devi AS, Suryanarayana M. Isolation/synthesis and characterization and potential impurities of an antifungal drug, fluconazole. Asian J Biochem Pharm Res 2011;1:201-8.

9. Muller L, Mauthe RJ, Riley CM, Andino MM, Antonis DD, Beels C, et al. A rationale for determining, testing, and controlling specific impurities in pharmaceuticals that possess potential for genotoxicity. Regul Toxicol Pharmacol 2006;44:198-211.

10. Aleksandra F, Darko M, Zdenko H, Marija G, Jelena K, Ranko S, et al. Developmental and transplacental genotoxicology: fluconazole. Mutat Res 2008;657:43-7.

11. Venugopal N, Reddy AVB, Madhavi V, Reddy KG, Madhavi $G$, Method development and validation study for quantitative determination of 2-chloromethyl-3, 4-dimethoxy pyridine hydrochloride a genotoxic impurity in pantoprazole active pharmaceutical ingredient (API) by LC/MS/MS. J Pharm Biomed Anal 2012;70:592-7.

12. Reddy AVB, Venugopal N, Madhavi G, Reddy KG, Madhavi V. A selective and sensitive UPLC-MS/MS approach for trace level quantification of four potential genotoxic impurities in zolmitriptan drug substance. J Pharm Biomed Anal 2013;84:84-9.

13. Rao MS, Rao SV, Babu KPR, Kumar PS, Sharma HK. Quantification of genotoxic impurities in amlodipine drug substance by LC-MS. Der Pharm Lett 2014;6:47-55.

14. Reddy AVB, Venugopal N, Madhavi G. A selective and sensitive LCMS/MS method for the simultaneous determination of two potential genotoxic impurities in celecoxib. J Anal Sci Technol 2014;5:18-25.

15. Wijk AMV, Beerman B, Niederlander HAG, Siebum AHG, Jong GJD. A new approach for generic screening and quantitation of potential genotoxic alkylation compounds by pre-column derivatization and LC-MS/MS analysis. Anal Bioanal Chem 2011;400:1375-85.

16. Szekely Gy, Henriques B, Gil M, Ramos A, Alvarez C. Design of experiments as a tool for LC-MS/MS method development for the trace analysis of the potentially genotoxic 4dimethylaminopyridine impurity in glucocorticoids. J Pharm Biomed Anal 2012;70:251-8.

17. Wijk AMV, Niederländer HAG, Siebum AHG, Vervaart MAT, Jong GJD. A new derivatization reagent for LC-MS/MS screening of potential genotoxic alkylation compounds. J Pharm Biomed Anal 2013;74:133-40.

18. Szekely G, Henriques B, Gil M, Alvarez C. Experimental design for the optimization and robustness testing of a liquid chromatography-tandem mass spectrometry method for the trace analysis of the potentially genotoxic 1,3-diisopropylurea. Drug Test Anal 2014;6:898-908.

19. Durga babu M, Surendrababu K, Kishore M. Development and validation of a gas chromatography-mass spectrometry with selected ion monitoring method for the determination of trace levels of methane sulfonyl chloride as an impurity in itraconazole active pharmaceutical ingredient. Asian J Pharm Clin Res 2016;9:403-7.

20. Natarajan S, Kempegowda BK, Bharathiar M. Determination of traceable genotoxic impurity chloroacetyl chloride a carcinogen by LC/MS/MS in drug substances. Asian J Pharm Clin Res 2016;9:97-100.

21. Hermawan D, Ali NAM, Ibrahim WAW, Sanagi MM. Analysis of fluconazole in the human urine sample by high performance liquid chromatography method. J Phys: Conf Ser 2013;423. Doi:10.1088/1742-6596/423/1/012009

22. Liew KB, Loh GOK, Tan YTF, Peh KK. Development and application of simple HPLC-UV method for fluconazole quantification in human plasma. Int J Pharm Pharm Sci 2012;4:107-11.

23. Al-rimawi F. Development and validation of analytical method for fluconazole and fluconazole related compounds (A, B, and C) in capsule formulations by HPLC with UV detection. Jordan J Chem 2009;4:357-65.

24. Dgither SA, Yusuf A, Hammami MM. Fluconazole: stability and analysis in human plasma by simple high performance liquid chromatography. J Pharm Sci 2009;34:179-86.

25. Kim SD, Im HT, Kang IM, Lee HS, Lee HW, Cho SH, et al. An optimized analytical method of fluconazole in human plasma by high-performance liquid chromatography with ultraviolet detection and its application to a bioequivalence study. J Chromatogr B 2007;852:174-9.

26. Porta V, Chang KH, Storpirtis S. Evaluation of the bioequivalence of capsules containing $150 \mathrm{mg}$ of fluconazole. Int J Pharm 2005;288:81-6.

27. Hillis J, Morelli I, Neville D, Fox J, Leary AC. The validation of a bioanalytical method for the determination of fluconazole in human plasma. Chromatographia 2004;59:S203-7.

28. Abdel-moety EM, Khattab FI, Kelani KM, Aboual-Alamein AM. Chromatographic determination of clotrimazole, ketoconazole and fluconazole in pharmaceutical formulations. Farmaco 2002;57:931-8.

\section{How to cite this article}

- L Narasimha Rao K, N Devanna, KVN Suresh Reddy. Method development and validation study for quantitative determination of genotoxic impurity and its precursor in fluconazole sample by liquid chromatography-tandem mass spectrometry. Int J Pharm Pharm Sci 2016;8(12):84-89. 